José Marcio Carvalho da Silva ${ }^{1}$

Murilo Mariz de Farias Neto ${ }^{2}$

\title{
INFECÇÃO HOSPITALAR E A \\ RESPONSABILIZAÇÃO CIVIL NOS \\ TRIBUNAIS BRASILEIROS
}

Nosocomial infection and civil liability in Brazilian courts

${ }^{1}$ Faculdade Estácio. Recife/PE, Brasil.

${ }^{2}$ Universidade Potiguar. Natal/RN, Brasil.

Correspondência: José Marcio Carvalho da Silva. E-mail: jmarciocarvalho@globo.com.

Recebido em: 20/02/2015. Revisado em: 26/04/2015. Aprovado em: 29/04/2015. 


\section{RESUMO}

A infecção hospitalar é notoriamente uma das principais problemáticas enfrentadas na atualidade pelas instituições prestadoras de serviço de saúde e pelos profissionais que nela atuam, fato este evidenciado pelo número crescente de ações propostas na Justiça pelos pacientes ou usuários. Surge, a partir desse cenário, o fenômeno da responsabilidade civil nos casos de infecção hospitalar. As implicações legais desse fenômeno são diversas e envolvem questões relacionadas ao ambiente institucional e à conduta profissional. Nesse sentido, o presente trabalho tem como objetivo analisar a literatura a respeito do posicionamento dos tribunais brasileiros em relação à responsabilização civil nos casos de infecção hospitalar. São elencados os aspectos conceituais que definem essa síndrome infecciosa e os tipos de responsabilidade civil, as diretrizes jurídicas que orientam a condução da temática e as decisões dos tribunais brasileiros que versam sobre a responsabilidade civil nesses casos. Foi constatado que os julgados têm sido amparados pela distinção entre a responsabilização civil objetiva e a subjetiva, além de estarem conduzidos pelo entendimento da relação de prestação de serviço existente entre a instituição ou profissional de saúde e o usuário ou paciente.

\section{Palavras-Chave}

Direito; Hospital; Infecção Hospitalar; Responsabilidade Civil; Saúde.

\section{ABSTRACT}

Nosocomial infection is notoriously one of the primary problems faced by healthcare institutions and by professionals who work for them. This fact is demonstrated by the growing number of legal actions proposed in the legal system by patients and users of the health care system. Because of this scenario, the phenomenon of civil liability has arisen in cases of nosocomial infection. The legal implications of this phenomenon are varied and involve issues of the institutional environment and of professional conduct. Thus, the current study seeks to analyze the literature on the decisions taken by Brazilian courts regarding civil liability in cases of nosocomial infection. Conceptual aspects that define this healthcare problem are listed, as are the types of civil liability, the legal directives that guide conduct regarding this topic, and the decisions of Brazilian courts that consider civil liability in these cases. It was determined that the courts have been supported by the distinction between objective civil liability and subjective civil liability; additionally, it was determined that these courts are guided by the understanding of the existing service relationship between the institution or health care professional and the patient or user of the health care system.

\section{Keywords}

Civil Liability; Health; Hospitals; Law; Nosocomial Infection. 


\section{Introdução}

Apesar de a tecnologia e o acesso aos serviços de saúde terem avançado nas últimas décadas, muitos ainda são os desafios a serem enfrentados na busca por uma assistência de qualidade e excelência. Um desses desafios é a infecção hospitalar, cuja ocorrência regular tem sido ilustrada pelas sucessivas ações impetradas por pacientes da rede pública ou por usuários de planos de saúde privados nos tribunais brasileiros.

A infecção hospitalar é considerada objeto de responsabilidade civil, o que permite afirmar ser uma condição causadora de dano cuja indenização deve ser cumprida, em juízo, pelos responsáveis, que podem ser hospitais, entidades mantenedoras de hospitais, Administração Publica e profissionais da área de saúde.

A constatação do grande número de relatos que cotidianamente chegam ao Judiciário versando sobre infecção hospitalar, tanto no âmbito privado quanto no público, deve instigar os envolvidos nesse cenário a intensificarem os esforços no sentido de compreender a problemática e agir de forma transformadora sobre ela. Para isso, é necessário discutir alguns conflitos relativos a essa matéria.

Nesse sentido, o presente estudo foi realizado por meio de consulta à literatura pertinente ao tema, contemplando a revisão dos preceitos teóricos e jurídicos que norteiam a problemática da infecção hospitalar e responsabilização civil. As fontes bibliográficas utilizadas incluíram periódicos, livros, monografias, dissertações, teses, leis, decisões judiciais e jurisprudências. A busca pelos julgados foi realizada em um site de busca eletrônico específico (www.jusbrasil.com.br), com a utilização das seguintes palavras-chave, isoladas ou combinadas: "infecção hospitalar", "responsabilização civil", "responsabilidade objetiva", "responsabilidade subjetiva", "responsabilidade hospitalar" e "responsabilidade do profissional médico". Para colecionar os julgados originais, obtendo-se as sentenças na íntegra, foram consultados os sítios eletrônicos dos respectivos tribunais.

A partir da exploração do conteúdo aqui descrito, pretende-se estimular a reflexão e discussão sobre como os tribunais brasileiros têm analisado os aspectos jurídicos atrelados à temática em questão.

\section{Infecção hospitalar e responsabilidade civil}

Antes de dar ensejo aos aspectos jurídicos da matéria proposta, faz-se necessário destacar conceitualmente a infecção hospitalar. Edson Batista e Sônia Marley Mourão Batista comentam sobre isso:

A Saúde, no Brasil, é um direito do povo e dever do Estado, retratado no artigo $6^{\circ} \mathrm{da} \mathrm{CF} / 88$. $\mathrm{O}$ avanço tecnológico trouxe-nos muitos benefícios na área da saúde, de forma a otimizar o exercício desse direito. No entanto, ao lado do atendimento médico e nosocomial de assistência, proteção e recuperação da saúde, dos 
medicamentos e dos equipamentos de ponta, temos o insidioso problema das infecções contraídas pelos pacientes durante a internação. É a chamada infecção hospitalar ${ }^{1}$.

Complementando a definição supracitada, leia-se a definição de Pereira e Moriya:

\begin{abstract}
Emprega-se a expressão infecção hospitalar de forma genérica e convencional para designar infecções adquiridas após a admissão do paciente no hospital e que se manifestam durante a internação ou após a alta, se puderem ser correlacionadas com a hospitalização [...] essa expressão não implica, necessariamente, que o micro-organismo responsável seja de origem hospitalar, mas identifica o hospital como lugar onde se contraiu a infecção ${ }^{2}$.
\end{abstract}

Vale ressaltar, ainda, que o termo “infecção hospitalar" aqui não se restringe apenas ao hospital, mas também abrange clínicas, prontos-atendimentos e instituições de saúde em geral ${ }^{3}$. Segundo Kfouri Neto ${ }^{4}$ e Almeida ${ }^{5}$, a infecção hospitalar pode ser explicada por duas possíveis hipóteses: contaminação direta por germes do ambiente hospitalar ou infecção a partir das condições clínicas do próprio paciente. Assim, o indivíduo pode ser acometido por infecções endógenas - ou seja, desenvolvidas por seu próprio organismo - ou por infecções exógenas - que são adquiridas através do contato com profissionais da saúde, artigos ou equipamentos médicos e hospitalares. Essa distinção é crucial no momento em que o paciente propõe uma ação judicial indenizatória em face dos supostos causadores de sua enfermidade, pois o correto esclarecimento do demandado poderá determinar a obtenção de êxito na demanda.

Ademais, entende-se que, mesmo sem a obrigação de resultado - ou seja, a garantia de cura -, as unidades prestadoras de serviços na área de saúde assumem a garantia de meio, pois devem assegurar inevitavelmente a incolumidade do paciente durante o período de internação, evitando danos de ordem patrimonial e extrapatrimonial ${ }^{6}$. No Brasil, o Ministério da Saúde e a Agência Nacional de Vigilância Sanitária (Anvisa) comungam a regulação e fiscalização das atividades das

\footnotetext{
${ }^{1}$ BATISTA, Édson; BATISTA, Sônia Marley Mourão. A responsabilidade civil de médicos e hospitais nos casos de infecção hospitalar. Revista Interdisciplinar NOVAFAPI, v. 3, n.2, p. 24-28, 2010.

2PEREIRA, Milca Severino; MORIYA, Tokico. Infecção hospitalar: estrutura básica de vigilância e controle. 2. ed. Goiânia: AB Ed., 1995. p. 5.

${ }^{3}$ SCREMIN, Natali. Responsabilidade civil dos hospitais e os índices de controle de infecção hospitalar. Revista Eletrônica do Curso de Direito da UFSM, v. 3, n. 1, p. 34-50, 2008. Disponível em: <http://cascavel.ufsm.br/ revistas/ojs-2.2.2/index.php/revistadireito/article/view/6826\#.Ve5MTpfITIU>. Acesso em: 29 set. 2015.

${ }^{4}$ KFOURI NETO, Miguel. Responsabilidade civil do médico. 8. ed. São Paulo: Ed. Revista dos Tribunais, 2013. p. 175.

${ }^{5}$ ALMEIDA, Álvaro Henrique Teixeira. A responsabilidade civil dos hospitais e clinicas. Disponivel em: <http://www.imiarj.com.br/Resp.Civil.pdf>. Acesso em: 05 dez. 2013.

${ }^{6}$ GOMES, Daniela Vasconcellos; GEWEHR, Mathias Felipe. Responsabilidade civil dos estabelecimentos hospitalares em caso de infecção hospitalar. Revista do Curso de Direito da FSG, v. 4, n. 7, p. 53-59, 2010. Disponível em: <http://ojs.fsg.br/index.php/direito/article/viewFile/597/476>. Acesso em: 29 set. 2015.
} 
Comissões de Controle de Infecção Hospitalar (CCIH), cuja presença nas unidades hospitalares é obrigatória por força da Lei n. 9.431/1997.

A referida lei define o Programa de Controle de Infecções Hospitalares (PCIH) como o "conjunto de ações desenvolvidas deliberada e sistematicamente com vistas à redução máxima possível da incidência e gravidade das infecções hospitalares". Por estarem devidamente organizadas, as CCIH podem executar suas atividades de forma continuada e profilática, minimizando a disseminação de agentes bacterianos no ambiente hospitalar e isolando imediatamente os casos identificados. A realização de treinamentos e palestras pelas referidas comissões ajuda a diminuir consideravelmente a ocorrência de infecções hospitalares, tendo em vista que as orientações prestadas às equipes multidisciplinares tendem a surtir efeitos gradativamente. Salienta-se, no entanto, que ambientes hospitalares não são completamente estéreis, uma vez que, no caso das infecções hospitalares endógenas, existe controle, mas não erradicação dos agentes causadores - considerando-se que eliminá-los totalmente implicaria na morte da microbiota humana normal, o que seria indesejável ${ }^{8}$.

Corroborando esse entendimento, podemos observar a Portaria Federal n. 2.616/GM/MS/1998 ${ }^{9}$, que traz em seu bojo um programa de controle de infecções hospitalares cujo principal intuito é a redução da incidência dessas infecções no âmbito hospitalar por meio da participação de uma equipe multidisciplinar, composta por vários profissionais da área de saúde:

A CCIH deverá ser composta por profissionais da área de saúde, de nível superior, formalmente designados.

2.2. Os membros da CCIH serão de dois tipos: consultores e executores.

2.2.1. O presidente ou coordenador da $\mathrm{CCIH}$ será qualquer um dos membros da mesma, indicado pela direção do hospital.

2.3. Os membros consultores serão representantes dos seguintes serviços:

2.3.1. Serviço médico;

2.3.2. Serviço de enfermagem;

2.3.3. Serviço de farmácia;

2.3.4. Laboratório de microbiologia;

2.3.5. Administração.

${ }^{7}$ BRASIL. Lei n. 9.431, de 6 de janeiro de 1997. Dispõe sobre a obrigatoriedade da manutenção de programa de controle de infecções hospitalares pelos hospitais do País. Disponível em: < http://www.planalto.gov.br/ ccivil_03/Leis/L9431.htm>. Acesso em: 10 de outubro de 2014.

8ZOBOLI, Elma Lourdes Campos Pavone. Erro médico e infecção hospitalar. Revista de Direito Sanitário, v. 3, n. 2, p. 124-136, 2002. Disponível em: <http://www.revistas.usp.br/rdisan/article/view/81248>. http://dx.doi.org/10.11606/issn.2316-9044.v3i2p124-136.

${ }^{9}$ BRASIL. Ministério da Saúde. Portaria n. 2.616/MS/GM, de 12 de maio de 1998. Disponível em: <http:// bvsms.saude.gov.br/bvs/saudelegis/gm/1998/prt2616_12_05_1998.html>. Acesso em: 05 out. de 2014. 
Dessa interação, surgirá para cada CCIH a responsabilidade de implementar normas, avaliar o programa de controle de infecção hospitalar e treinar os profissionais e funcionários da instituição, buscando com isso transformá-los em multiplicadores de informações e atitudes relacionadas à prevenção e ao controle das infecções hospitalares. Falhas nessas determinações extrapolam a esfera do ambiente institucional e alcançam o âmbito jurídico, no qual cabe discutir a infecção hospitalar na perspectiva da responsabilização civil. De acordo com Edson Batista e Sônia Marley Mourão Batista ${ }^{10}$, "sempre que alguém age como não deveria ter agido pode ser responsabilizado e coagido a indenizar o dano que sua conduta tenha causado". Os mesmos autores ${ }^{11}$ comentam, ainda, que "tem responsabilidade civil de indenizar quem causa dano a outrem, seja por não honrar um contrato, seja por ter praticado um ato contrário ao direito". Portanto, quando a prática médico-hospitalar não é executada de forma apropriada, causando dano, coloca-se em risco a saúde, direito fundamental garantido desde 1988 pela Constituição Federal do Brasil ${ }^{12}$. É nesse sentido que se evoca o direito e sua análise em relação à responsabilização civil.

De acordo com a teoria clássica, presume-se a culpa como fundamento da responsabilidade civil, podendo esta responsabilização civil ser estudada de duas maneiras distintas, a saber: responsabilidade objetiva e responsabilidade subjetiva. Para efeito de maior segurança jurídica e compreensão da dimensão da problemática da infecção hospitalar sob o prisma da responsabilização civil, é de extrema importância conhecer e distinguir ambas, pois suas consequências no direito são antagônicas.

A responsabilidade civil subjetiva apoia-se na ideia de que, não havendo culpa, não há responsabilidade, passando a ser a prova de culpa um pressuposto necessário do dano relatado. Já a responsabilidade civil objetiva prescinde da culpa e se satisfaz apenas com o dano e o nexo de causalidade, ou seja, implica na reparação de um dano mesmo na ausência de culpa ${ }^{13}$. A responsabilidade civil objetiva é atribuída aos hospitais, clinicas e casas de saúde, e a responsabilidade civil subjetiva é geralmente aplicada aos casos em que os profissionais de saúde são chamados para compor a lide como partes demandadas. A clareza em relação a esses conceitos é fundamental para subsidiar a identificação de quem será convocado a litigar em juízo, se a instituição hospitalar ou o profissional de saúde responsável.

\footnotetext{
${ }^{10}$ BATISTA, Édson; BATISTA, Sônia Marley Mourão. op. cit., p. 32.

${ }^{11}$ Id. Ibid., p. 32.

${ }^{12}$ BRASIL. Constituição da República Federativa do Brasil de 1988. Disponível em: <http://www.planalto.gov. br/ccivil_03/constituicao/ConstituicaoCompilado.htm>. Acesso em: 16 set. 2015.

${ }^{13}$ GONÇALVES, Carlos Roberto. Direito civil brasileiro: responsabilidade civil. 4. ed. São Paulo: Saraiva, 2010. v. 4, 2010.
} 


\section{Responsabilidade civil objetiva e subjetiva}

Inicialmente, é necessário pontuar que a conduta jurídica atual nos casos de infecção hospitalar é guiada de forma preponderante pelo Código de Defesa do Consumidor (CDC), uma vez que entre prestador e paciente está caracterizada uma relação de consumo, em que o primeiro encontra-se obrigado a reparar os danos que eventualmente venha a causar por defeitos oriundos na prestação de serviços ao segundo. Fica clara, portanto, a condição de contrato estabelecido entre prestador de serviço e paciente - contrato este que, segundo Scremin ${ }^{14}$, "dispensa qualquer formalidade ou pressuposto especial, podendo, portanto, se dar de forma verbal, escrita, expressa, tácita, onerosa ou gratuita”.

Percebe-se que os tribunais brasileiros têm entendido a maioria dos casos de infecção hospitalar na perspectiva da responsabilidade objetiva, tendo em vista que o risco de infecção é inerente à atividade do ambiente hospitalar, conforme reza preceito do CDC em seu artigo $6^{\circ}$. Assim sendo, a responsabilidade civil dos prestadores de serviços de saúde nos casos de infecção hospitalar é classificada como objetiva nos termos do artigo $14^{\circ}$ do CDC, sendo estabelecida a possibilidade de inversão do ônus da prova (cabe ao prestador provar que não houve relação direta entre uma conduta imediata anterior ao ocorrido e o dano causado, pois somente assim afasta-se a possibilidade de ser o prestador o agente causador da referida infecção). Sobre isso, comentam Gomes e Gewehr:

Quanto à prova, o ônus é geralmente do fornecedor, em razão da inversão do ônus da prova nas relações de consumo, com base nos princípios da isonomia e do atendimento à função social do contrato. A inversão do ônus da prova nas relações de consumo é uma manifestação do reconhecimento da dificuldade do consumidor em assegurar seus direitos, em especial quanto à prova de algum dano sofrido ${ }^{15}$.

Apesar da presunção de culpa ser uma corrente plenamente aceita nos casos de infecção hospitalar, existem defensores da responsabilidade objetiva na modalidade da teoria do risco criado, "pela qual o dever do agente de indenizar decorre simplesmente do risco gerado pelo exercício da sua profissão ou do desenvolvimento de determinada atividade", de acordo com Scremin ${ }^{16}$. Sobre isso, essa mesma autora ainda pondera:

Em vista disso, entende-se que o parágrafo único do art. 927 do Código Civil, que consagra a responsabilidade objetiva e a teoria do risco, bem como o art. $14, \$ 1^{\circ}$ do $\mathrm{CDC}$ e seus incisos não

\footnotetext{
${ }^{14}$ SCREMIN, Natali. op. cit., p. 40.

${ }^{15}$ GOMES, Daniela Vasconcellos; GEWEHR, Mathias Felipe. op. cit., p. 59.

${ }^{16}$ SCREMIN, Natali. op. cit., p. 40.
} 
podem ser interpretados sem levar em conta as peculiaridades do contrato hospitalar. Em se tratando de infecção hospitalar, deve ser considerada, principalmente, a impossibilidade de se obter índice zero de infecção e a influência determinante das condições do paciente para a ocorrência da infecção ${ }^{17}$.

Já a responsabilidade civil subjetiva, conforme previamente citado, é facultada ao profissional de saúde quando a este é atribuída culpa pelo dano. Sobre culpa, França comenta:

A teoria subjetiva tem na culpa seu fundamento basilar. No âmbito das questões civis, a expressão culpa tem sentido muito amplo. Vai desde a culpa stricto sensu ao dolo. É o elemento do ato ilícito, em torno do qual a ação ou omissão levam à existência de um dano. Não é sinônimo, portanto, de dano. É claro que só existirá culpa se dela resultar um prejuízo. Todavia, esta teoria não responsabiliza a pessoa que se portou de maneira irrepreensível, distante de qualquer censura, mesmo que tenha causado um dano ${ }^{18}$.

Portanto, enquanto a responsabilização das instituições prestadoras de serviços de saúde é objetiva, em algumas ações judiciais o profissional médico figura na lide de forma solidária. No entanto, faz-se necessário esclarecer que sua responsabilidade civil é subjetiva, e o demandante será incumbido da comprovação de que houve imprudência, negligência ou imperícia por parte desse profissional. Uma vez comprovados os requisitos anteriormente mencionados, surge para o profissional a obrigação de indenizar para reparar o dano. Sem a comprovação de culpa, a lide encontra-se fadada ao insucesso e o pleito por uma possível indenização, comprometido.

Deve-se frisar que, em determinadas situações, o profissional de saúde pode ser julgado sob o prisma da responsabilidade objetiva, especialmente quando tal profissional assume obrigação de resultado, conforme destaca Vasconcelos:

A atividade do médico apresenta-se, na maioria dos casos, como obrigação de meios, porém, em boa parte, também assume esse profissional obrigação de resultado (a exemplo da cirurgia plástica, radiologia, anatomopatologia), devendo, nesses casos, apurar-se objetivamente a responsabilidade, afastando-se os pressupostos da avaliação da culpa e fixando-se a relação causal entre o fato e o dano ${ }^{19}$.

\footnotetext{
${ }^{17}$ SCREMIN, Natali. op. cit., p. 41.

${ }^{18}$ FRANÇA, Genival Veloso. Direito médico. 11. ed. Rio de Janeiro: Forense, 2013. p. 268.

${ }^{19}$ VASCONCELOS, Fernando. Proteção do consumidor na área da saúde: responsabilidade civil de médicos, hospitais e planos de saúde. Revista Direito e Desenvolvimento, v. 2, n. 4, p. 266-281, 2011. p. 280.
} 
A infecção hospitalar decorrente da conduta profissional inadequada deve ficar provada e não pode ser verificada por presunções ${ }^{20}$. Vale salientar que a responsabilização do profissional de saúde nos tribunais de justiça merece ser avaliada com especial prudência, tendo em vista que os magistrados não possuem formação técnica para elucidar todos os casos a eles direcionados, sendo necessária a designação de um perito do juízo, profissional que geralmente possui formação na área relacionada com a lide e que deverá manter-se imparcial. Comprovada a culpa, esta não necessariamente deve ser de grandes proporções, bastando ser certa, tendo em vista que a proporcionalidade e a gravidade da conduta servirão apenas para quantificar os valores pecuniários nos casos em que ocorrer uma provável indenização. Para além da indenização, deve-se pensar também na responsabilidade civil como instrumento jurídico de função sancionatória e preventiva que contribua para a coibição da prática de outros atos danosos, tanto pela pessoa que o cometeu quanto por quaisquer outros ${ }^{21}$.

Apesar disso, em alguns casos de responsabilidade objetiva o indivíduo estará amparado pelas excludentes de responsabilidade. Ou seja, embora o resultado traga danos, o indivíduo não estará obrigado a repará-los por estar amparado pela lei, como no caso fortuito ou força maior, ou quando resta comprovado que o resultado do evento deu-se em razão de culpa exclusiva da vítima - exemplos que abordaremos a seguir, pois os mesmos darão origem à responsabilidade sem culpa.

Em relação ao caso fortuito ou força maior, Venosa pontua:

Ambas as figuras equivalem-se, na prática, para afastar o nexo causal, para alguns autores, caso fortuito se ligaria aos critérios de imprevisibilidade e irresistibilidade. Assim o caso fortuito seria aquela situação normalmente imprevisível, fato da natureza ou fato humano. A força maior seria caracterizada por algo também natural ou humano a que não se poderia resistir, ainda que possível prever sua ocorrência ${ }^{22}$.

Analisando essa colocação, conclui-se que o referido conceito vincula-se a dois fatores essenciais para sua existência, ou seja, a imprevisibilidade ou a inevitabilidade do evento danoso, vinculado à ausência de culpa. Visualizamos um exemplo muito comum de caso fortuito ou força maior quando atendimentos médicos são prestados a pacientes que chegam em estado gravíssimo nas principais urgências dos grandes hospitais do país, necessitando de intervenção cirúrgica imediata. Embora o médico esteja cercado de todos os cuidados necessários, o paciente pode inevitavelmente ir a óbito ou adquirir uma infecção devido à fragilidade de seu estado de saúde. Nesses casos, não seria justo atribuir culpa ao profissional que trabalhou no

\footnotetext{
${ }^{20}$ BATISTA, Édson; BATISTA, Sônia Marley Mourão. op. cit., p. 34.

${ }^{21}$ ALMEIDA, Álvaro Henrique Teixeira. op. cit.

${ }^{22}$ VENOSA, Sílvio de Salvo. Direito civil: responsabilidade civil. 10. ed. São Paulo: Atlas, 2010. p. 60.
} 
intuito de manter a vida do paciente, mas que, em razão de causa fortuita ou força maior, não logrou o êxito esperado.

Outra excludente de responsabilidade civil muito suscitada diz respeito à culpa exclusiva da vítima. Segundo o entendimento de Gonçalves, a culpa exclusiva da vítima faz com que desapareça a responsabilidade do agente.

Quando o evento danoso acontece por culpa exclusiva da vítima, desaparece a responsabilidade do agente. Nesse caso, deixa de existir a relação de causa e efeito entre o seu ato e o prejuízo experimentado pela vítima. Pode-se afirmar que, no caso de culpa exclusiva da vítima, o causador do dano não passa de mero instrumento do acidente. Não há liame de casualidade entre o seu ato e o prejuízo da vítima ${ }^{23}$.

Essas considerações são de grande valia nos casos de pacientes que não seguem as devidas orientações médicas e, em decorrência desta falta de cuidado, venham a desenvolver infecção após o internamento. Desta feita, não se pode atribuir ao profissional médico a responsabilização pelo fato danoso, haja vista que todas as orientações e informações foram transmitidas de forma clara e objetiva, embora o paciente não as tenha seguido.

\section{Infecção hospitalar em julgados dos tribunais brasileiros}

Destacam-se a seguir alguns casos sobre responsabilidade civil que tramitaram nos tribunais brasileiros, envolvendo cidadãos que acionaram o Poder Judiciário em busca de reparação alegando serem vítimas de infecção hospitalar.

Na Apelação Cível n. 70046722195, do Tribunal de Justiça do Estado do Rio Grande do Sul, está claro o entendimento do relator desembargador Paulo Roberto Lessa Franz no que diz respeito à responsabilidade civil obrigatória do hospital, que, independentemente de culpa, deve assumir o reparo do dano, especialmente na ausência de provas que atestem a instalação das medidas prévias cabíveis que a instituição deve prover para evitar esse tipo de ocorrência. O julgado considera em sua sentença a reparação por dano extrapatrimonial e subsidia seus argumentos com os princípios da proporcionalidade e razoabilidade.

APELAÇÃO CÍVEL. RESPONSABILIDADE CIVIL. AÇÃO DE REPARAÇÃO DE DANOS MORAIS E MATERIAIS. INFECÇÃO HOSPITALAR. RESPONSABILIDADE CIVIL DO NOSOCÔMIO. É cediço que os hospitais, na qualidade de prestadores de serviços, respondem independente de culpa pelo serviço defeituoso prestado ou posto à disposição do consumidor, responsabilidade

\footnotetext{
${ }^{23}$ GONÇALVES, Carlos Roberto. op. cit., p.463.
} 
que é afastada sempre que comprovada a inexistência de defeito ou a culpa exclusiva do consumidor, ou de terceiro, ex vi do art. $14, \S$ $3^{\circ}$ do CDC. Hipótese em que restou devidamente comprovada a infecção hospitalar sofrida pela demandante nas dependências do hospital réu, logo após cirurgia no joelho, impondo-se o reconhecimento da falha na prestação de serviço pelo nosocômio demandado e, por conseguinte, o dever de indenizar. Ausência de prova de que o hospital tenha adotado as medidas cabíveis para evitar esse tipo de intercorrência. Dever de indenizar que se reconhece.

DANO MORAL. CONFIGURAÇÃO. São incomensuráveis a dor e o sofrimento suportados pela autora, ante os transtornos causados com a situação, estando caracterizado o danum in re ipsa, o qual se presume, conforme as mais elementares regras da experiência comum, prescindindo de prova quanto ao prejuízo concreto.

QUANTUM INDENIZATÓRIO. MANUTENÇÃO. Na fixação da reparação por dano extrapatrimonial, incumbe ao julgador, atentando, sobretudo, para as condições do ofensor, do ofendido e do bem jurídico lesado, e aos princípios da proporcionalidade e razoabilidade, arbitrar quantum que se preste à suficiente recomposição dos prejuízos, sem importar, contudo, enriquecimento sem causa da vítima. A análise de tais critérios, aliada às demais particularidades do caso concreto, bem como aos parâmetros utilizados por esta Câmara, em situações análogas, conduz à manutenção do montante indenizatório no valor de $\mathrm{R} \$ 15.000,00$ (quinze mil reais), acrescidos de juros e correção monetária nos termos da condenação ${ }^{24}$.

O julgado é categórico no que se refere à configuração do dano moral, cujo transtorno é incomensurável cientificamente, mas envolve condições de constrangimento, dor e sofrimento ao lesado. Nesse sentido, ressarcimento do dano causado e prevenção de novos danos compõem uma dupla função na indenização por dano moral $^{25}$. Configura-se, portanto, uma medida não apenas compensatória ao lesado, mas educativa e inibitória ao causador do dano.

Com relação ao julgado a seguir, observa-se que sua fundamentação encontra-se pautada na responsabilidade objetiva dos entes públicos, conforme disposição expressa no artigo 37, parágrafo $6^{\circ}$ da Constituição Federativa do Brasil de $1988^{26}$ :

\footnotetext{
${ }^{24}$ TRIBUNAL DE JUSTIÇA DO RIO GRANDE DO SUL. Apelação Cível n. 70046722195 da $10^{\text {a }}$ Câmara Civil do Tribunal de Justiça do Rio Grande do Sul. Relator: Paulo Roberto Lessa Franz. Disponível em: <http://www. tjrs.jus.br/site_php/consulta/download/exibe_documento.php?ano=2012\&codigo=173923>. Acesso em: 20 jun. 2014.

${ }^{25}$ GOMES, Daniela Vasconcellos; GEWEHR, Mathias Felipe. op. cit., p. 62.

${ }^{26}$ Art. 37, §6. BRASIL. Constituição da República Federativa do Brasil de 1988, cit.
} 
Art. 37. A administração pública direta e indireta de qualquer dos Poderes da União, dos Estados, do Distrito Federal e dos Municípios obedecerá aos princípios de legalidade, impessoalidade, moralidade, publicidade e eficiência.

$\$ 6^{\circ}$ As pessoas jurídicas de direito público e as de direito privado prestadoras de serviços públicos responderão pelos danos que seus agentes, nessa qualidade, causarem a terceiros, assegurado o direito de regresso contra o responsável nos casos de dolo ou culpa.

O julgado do relator Camargo Pereira na Apelação n. 389439420078260405, do Tribunal de Justiça do Estado de São Paulo, restou caracterizada a responsabilidade objetiva do município em uma ação de indenização por danos morais e materiais em razão de infecção hospitalar adquirida por irregularidades no atendimento médico prestado em uma unidade hospitalar.

RESPONSABILIDADE OBJETIVA DO MUNICÍPIO. INDENIZAÇÃO POR DANOS MORAIS E MATERIAIS. IRREGULARIDADES NO ATENDIMENTO MÉDICO. INFECÇÃO HOSPITALAR. 1. O hospital responde objetivamente, visto que a infecção hospitalar constitui risco inerente à sua atividade, porquanto lhe cabe o dever de zelar pela saúde do paciente, porque dispõe dos meios necessários ao trato e à conservação da saúde do paciente. 2. A prova dos autos é conclusiva de que a infecção foi adquirida após a internação. Certamente ocorreu por falha na assepsia, seja durante o procedimento cirúrgico, seja no pós-operatório, seja ainda nas instalações do hospital. Recurso provido ${ }^{27}$.

A apreciação da matéria pelo Supremo Tribunal de Justiça corrobora os posicionamentos anteriores, conforme julgamento do Recurso Especial n. 629.212/RJ:

RESPONSABILIDADE CIVIL. CONSUMIDOR. INFECÇÃO HOSPITALAR. RESPONSABILIDADE OBJETIVA DO HOSPITAL. ART.14 DO CDC. DANO MORAL. QUANTUM INDENIZATÓRIO. O hospital responde objetivamente pela infecção hospitalar, pois esta decorre do fato da internação e não da atividade médica em si. O valor arbitrado a título de danos morais pelo Tribunal a quo não se revela exagerado ou desproporcional às peculiaridades da espécie, não justificando a

\footnotetext{
${ }^{27}$ TRIBUNAL DE JUSTIÇA DO ESTADO DE SÃO PAULO. Apelação n. 389439420078260405 da $3^{a}$ Câmara de Direito Público do Tribunal de Justiça do Estado de São Paulo. Relator: Camargo Pereira. Disponível em: <http://tj-sp.jusbrasil.com.br/jurisprudencia/22241027/apelacao-apl-389439420078260405-sp0038943-9420078260405-tjsp>. Acesso em: 18 jun. 2014.
} 
excepcional intervenção desta corte para revê-lo. Recurso especial não conhecido ${ }^{28}$.

Não obstante, faz-se necessário pontuar a existência de decisões judiciais que julgaram improcedente o pleito de pacientes que ingressaram em juízo reivindicando reparações e indenizações por danos morais e materiais em decorrência de infecção hospitalar que, segundo esses pacientes, foram adquiridas após atos cirúrgicos ou internações hospitalares. Exemplo desse tipo de julgado é a Apelação Cível n. 10105082677813001, do Tribunal de Justiça do Estado de Minas Gerais, na qual o relator afasta o nexo causal e julga improcedente o pedido.
AÇÃO DE INDENIZAÇÃO POR DANOS MATERIAIS MORAIS - INFECÇÃO HOSPITALAR - RESPONSABILIDADE OBJETIVA DO HOSPITAL - NEXO CAUSAL - AUSÊNCIA DE PROVAS - PEDIDO IMPROCEDENTE - DECISÃO MANTIDA. Ausente à prova de que a infecção que acometeu o organismo da apelante ocorreu durante o tempo de internação para a realização do procedimento cirúrgico nas dependências do hospital apelado, ou que decorreu da ineficácia dos procedimentos adotados para o controle de infecção hospitalar, segundo os padrões exigidos pela vigilância sanitária, e, via de consequência, de que houve inexe- cução do contrato de prestação de serviços por este último, resta afastar o nexo causal, o que impõe a improcedência do pedido ${ }^{29}$.

A referida ação indenizatória foi declarada improcedente em razão da ausência de provas de que a infecção desenvolvida pelo apelante se dera durante sua permanência nas instalações daquela unidade hospitalar, ou então que houvera algum tipo de falha no serviço prestado pela $\mathrm{CCIH}$, fato este que não prosperaria vez que o referido setor cumpria com todas as exigências da vigilância sanitária. Quebrado o nexo de causalidade entre o dano sofrido e a conduta do hospital, este não foi responsabilizado. As colocações de Scremin aplicam-se à decisão supracitada, pois incidem sobre os casos em que o nexo causal é afastado:

Assim, uma vez provada pelo nosocômio a realização de todos os procedimentos e providências cabíveis para evitar a infecção hospitalar, eventual infecção contraída pelo paciente não pode gerar automaticamente o dever de indenizar, pois, então, estar-se-ia imputando à instituição uma responsabilidade sem causa. O dever

\footnotetext{
${ }^{28}$ BRASIL. Supremo Tribunal de Justiça. Recurso Especial n. 629.212/RJ da $4^{a}$ turma do Supremo Tribunal de Justiça. Relator: Ministro César Asfor Rocha. Disponível em: <http://stj.jusbrasil.com.br/jurisprudencia/8887586/recurso-especial-resp-629212-rj-2004-0019175-2/relatorio-e-voto-13997472>. Acesso em: 18 jun. 2014.

${ }^{29}$ TRIBUNAL DE JUSTIÇA DE MINAS GERAIS. Apelação Cível n. 10105082677813001. Relator: Batista de Abreu. Disponivel em: <http://www8.tjmg.jus.br/themis/baixaDocumento.do?numeroVerificad or $=101050826778130012013735695>$. Acesso em: 20 jun. 2014.
} 
de reparar apenas deverá ser imputado ao hospital, se o paciente consumidor comprovar que este falhou no seu dever de precaução ${ }^{30}$.

É notório que o risco de infecção é evidenciado com mais intensidade no ambiente hospitalar quando comparado a espaços menos expostos à proliferação dos agentes disparadores dessa condição. Embora cuidados de higienização, desinfecção ou esterilização sejam condições sine qua non no nosocômio, percebe-se que as condutas dos profissionais de saúde nem sempre atendem as medidas profiláticas necessárias. Por outro lado, sabe-se que em alguns casos a gravidade do quadro de saúde do paciente, sua debilidade imunológica e sua idade avançada são consideradas fatores de risco que podem ocasionar uma provável infecção hospitalar. Além disso, cirurgias delicadas e consideradas de grande porte tendem a ser mais demoradas e complexas, deixando o paciente mais exposto, conforme sentença proferida na Apelação n. 1496996120068260000, do Tribunal de Justiça do Estado de São Paulo.

RESPONSABILIDADE CIVIL INFECÇÃO HOSPITALAR conjunto probatório a demonstrar que a ré não agiu com desídia nos cuidados com o paciente CULPA NÃO COMPROVADA EM QUALQUER DE SUAS MODALIDADES (NEGLIGÊNCIA, IMPRUDÊNCIA OU IMPERÍCIA) RISCO DECORRENTE DA PRÓPRIA CIRURGIA DE GRANDE PORTE, EM MUITO AGRAVADO PELO PRECÁRIO ESTADO DE SAÚDE DO FALECIDO AUTOR - AÇÃO JULGADA IMPROCEDENTE - SENTENÇA RATIFICADA, COM APLICAÇÃO DO DISPOSTO NO ART.252 DO REGIMENTO INTERNO DO TRIBUNAL DE JUSTIÇA DO ESTADO DE SÃO PAULO RECURSO DESPROVIDO ${ }^{31}$.

Outro aspecto que tange à temática da responsabilização civil nos casos de infecção hospitalar versa sobre o fato de os profissionais de saúde e as instituições prestadoras de serviço de saúde comporem a lide de maneira solidária. Provocado a posicionar-se com relação à matéria, o Superior Tribunal de Justiça (STJ), consolidou o seguinte entendimento ${ }^{32}$ : "'a responsabilidade do hospital e a do médico têm fundamentos diversos, o que denota a impropriedade da denunciação à lide nessas circunstâncias". Gondim e Steiner complementam:

Em suma, reconhecendo que a responsabilidade do profissional gira em torno da culpa, sua integração à lide resultaria na instauração de lide secundária com fundamento diverso, uma vez

\footnotetext{
${ }^{30}$ SCREMIN, Natali. op. cit., p.42.

${ }^{31}$ TRIBUNAL DE JUSTIÇA DO ESTADO DE SÃO PAULO. Apelação n. 1496996120068260000 da $1^{a}$ Câmara de Direito Privado. Relator: Elliot Akel. Disponível em: < http://tj-sp.jusbrasil.com.br/jurisprudencia/20333039/ apelacao-apl-1496996120068260000-sp-0149699-6120068260000>. Acesso em: 28 jun. 2014.

${ }^{32}$ BRASIL. Superior Tribunal de Justiça. Recurso Especial n. 883.685. Relator: Ministro Fernando Gonçalves. Disponivel em: < https://ww2.stj.jus.br/processo/revista/documento/mediado/?componente=ITA\&sequenc ial=862725\&num_registro=200601652428\&data=20090316\&formato=PDF>. Acesso em: 10 ago. 2014.
} 
que o hospital responde objetivamente pelos danos causados em suas dependências ${ }^{33}$.

É oportuno lembrar que cabe à direção da instituição prestadora de serviço de saúde ingressar com ação de regresso em face dos profissionais que realizaram os procedimentos que causaram infecção e pelos quais a instituição foi condenada a reparar o dano. Todavia, deverá existir a comprovação de que os profissionais atuaram com negligência, imprudência ou imperícia. Há, portanto, clemência por rigorosa análise desse tipo de caso, no qual pode existir bipartição da responsabilidade, salvo contrato com ressalva expressa ${ }^{34}$.

Em outro julgado ${ }^{35}$, o STJ faz considerações a respeito do fato de o autor da ação ter procurado o hospital pela excelência de seu atendimento, e não por conta de um determinado profissional que faz parte de seu corpo clínico. Sobre isso, Gondim e Steiner comentam:

[...] a denunciação da lide ao médico deve ser analisada no caso concreto, havendo de ser indeferida quando não se achar configurado que houve escolha pessoal na contratação do médico ${ }^{36}$.

Extrai-se desse fato que, uma vez o paciente dirigindo-se por conta própria a uma unidade hospitalar em razão dos serviços prestados por este ou pela estrutura física oferecida, configura-se a responsabilidade objetiva do prestador em caso de infecção hospitalar. Deve-se levar em consideração o quadro de profissionais que compõe o referido hospital, porém estes apenas responderão de maneira subjetiva quando comprovados todos os requisitos necessários e exigidos para tal - ou seja, negligência, imprudência ou imperícia.

Cabe ainda frisar a colocação de Gomes e Gewehr no que diz respeito ao caráter não apenas punitivo, mas também educativo que as decisões judiciais devem ter:

Se reiteradamente ocorrem danos decorrentes da má prestação de serviços hospitalares, é porque alguns responsáveis por estabelecimentos de saúde ainda acreditam que não se aplicará efetivamente a norma substantiva que determina a reparação dos danos causados. Quanto mais efetiva for a condenação, maior será o cuidado para que não se pratiquem atos lesivos, evitando a exposição de consumidores e terceiros a danos patrimoniais e extrapatrimonais ${ }^{37}$.

\footnotetext{
${ }^{33}$ GONDIM, Glenda Gonçalves; STEINER, Renata Carlos. Responsabilidade civil médica: breves considerações em face da recente jurisprudência do Superior Tribunal de Justiça. Revista da Faculdade de Direito da UFG, v. 33, n. 1, p. 204-219, 2009. Disponivel em: <http://www.revistas.ufg.br/index.php/revfd/article/view/9844>. Acesso em: 29 set. 2015.

${ }^{34}$ VASCONCELOS, Fernando. op. cit., p. 276.

${ }^{35}$ BRASIL. Superior Tribunal de Justiça. Recurso Especial n. 445.845. Relator: Ministro Aldir Passarinho Junior. Disponível em: < https://ww2.stj.jus.br/processo/revista/documento/mediado/?componente=ITA\&sequenc ial=427148\&num_registro=200200804090\&data=20031013\&formato=PDF $>$. Acesso em: 10 ago. 2014.

${ }^{36}$ GONDIM, Glenda Gonçalves; STEINER, Renata Carlos. op. cit., p.213.

${ }^{37}$ GOMES, Daniela Vasconcellos; GEWEHR, Mathias Felipe. op. cit., p. 63.
} 


\section{Considerações finais}

A partir dos julgados analisados neste artigo, nota-se que alguns tribunais nacionais têm agido com ponderação ao averiguar, em suas decisões, se de fato houve falhas na conduta médico-hospitalar que justifiquem o quadro de infecção ou se esta ocorreu em decorrência de fatores inerentes aos procedimentos adotados.

Percebe-se de forma inconteste nos julgados a aplicação do arcabouço teórico pertinente aos diferentes tipos de responsabilização civil. Além disso, as sentenças têm sido guiadas regularmente pelos preceitos do CDC, estando explícita a relação de consumo por meio das condições de contratado e contratante imputadas, respectivamente, à instituição prestadora de serviço de saúde e ao usuário ou paciente.

O número crescente de ações julgadas sobre o tema em questão pode ser explicado no esteio de diferentes perspectivas. É possível que a população esteja cada vez mais empoderada no que se refere à postulação dos seus direitos, resultando em um aumento gradativo no número de ações na Justiça. Outra possibilidade é vislumbrar o aumento no número de casos de infecção hospitalar denunciados nos tribunais como um reflexo da situação caótica da estrutura das instituições de saúde brasileiras e das deficiências na formação dos profissionais que nelas estão inseridos.

Independentemente da causa, fato é que no Brasil a Justiça parece enfrentar essa problemática com frequência paulatina e, portanto, deve manter-se corretamente instrumentalizada para garantir às partes envolvidas decisões coerentes, íntegras, procedentes e fundamentadas, alinhadas com os axiomas previstos nos dispositivos legais apropriados. Almeja-se que as sentenças judiciais relacionadas à temática aqui abordada transpareçam que a Justiça está sensível e atenta a esses casos. Espera-se que os julgados não fiquem restritos apenas ao caráter meramente punitivo e reparatório, mas que reverberem positivamente na melhoria dos serviços prestados à comunidade e coíbam a reiteração dos casos de infecção hospitalar.

\section{Referências}

ALMEIDA, Álvaro Henrique Teixeira. A responsabilidade civil dos hospitais e clinicas. Disponível em: <http://www.imiarj.com.br/Resp.Civil.pdf>. Acesso em: 05 dez. 2013.

BATISTA, Édson; BATISTA, Sônia Marley Mourão. A responsabilidade civil de médicos e hospitais nos casos de infecção hospitalar. Revista Interdisciplinar NOVAFAPI, v. 3, n.2, p. 24-28, 2010.

FRANÇA, Genival Veloso. Direito médico. 11. ed. Rio de Janeiro: Forense, 2013.

GOMES, Daniela Vasconcellos; GEWEHR, Mathias Felipe. Responsabilidade civil dos estabelecimentos hospitalares em caso de infecção hospitalar. Revista do Curso de Direito da FSG, v. 4, n. 7, p. 53-59, 2010. Disponível em: <http://ojs.fsg.br/index.php/direito/article/ viewFile/597/476>. Acesso em: 29 set. 2015. 
GONÇALVES, Carlos Roberto. Direito civil brasileiro: responsabilidade civil. 4. ed. São Paulo: Saraiva, 2010. v. 4.

GONDIM, Glenda Gonçalves; STEINER, Renata Carlos. Responsabilidade civil médica: breves considerações em face da recente jurisprudência do Superior Tribunal de Justiça. Revista da Faculdade de Direito da UFG, v. 33, n. 1, p. 204-219, 2009. Disponível em: <http://www.revistas.ufg.br/index.php/revfd/article/view/9844>. Acesso em: 29 set. 2015.

KFOURI NETO, Miguel. Responsabilidade civil do médico. 8. ed. São Paulo: Ed. Revista dos Tribunais, 2013.

PEREIRA, Milca Severino; MORIYA, Tokico. Infecção hospitalar: estrutura básica de vigilância e controle. 2. ed. Goiânia: AB Ed., 1995.

SCREMIN, Natali. Responsabilidade civil dos hospitais e os índices de controle de infecção hospitalar. Revista Eletrônica do Curso de Direito da UFSM, v. 3, n. 1, p. 34-50, 2008. Disponível em: <http://cascavel.ufsm.br/revistas/ojs-2.2.2/index.php/revistadireito/article/view/6826\#. Ve5MTpflTIU>. Acesso em: 29 set. 2015.

VASCONCELOS, Fernando. Proteção do consumidor na área da saúde: responsabilidade civil de médicos, hospitais e planos de saúde. Revista Direito e Desenvolvimento, v. 2, n. 4, p. 266-281, 2011.

VENOSA, Sílvio de Salvo. Direito civil: responsabilidade civil. 10. ed. São Paulo: Atlas, 2010.

ZOBOLI, Elma Lourdes Campos Pavone. Erro médico e infecção hospitalar. Revista de Direito Sanitário, v. 3, n. 2, p. 124-136, 2002. Disponível em: < http://www.revistas.usp.br/rdisan/ article/view/81248>. http://dx.doi.org/10.11606/issn.2316-9044.v3i2p124-136.

José Marcio de Carvalho Silva - Pós-Graduado em Direito Civil e Processo Civil pela Faculdade Estácio (Recife/PE); pós-graduado em Direito Médico e da Saúde pela Universidade Potiguar (Natal/RN); graduado em Direito pela Faculdade Mauricio de Nassau (Recife/PE). Recife/PE, Brasil.E-mail: jmarciocarvalho@globo.com.

Murilo Mariz de Farias Neto - Pós-Graduação em Direito Civil e Empresarial pela Universidade Potiguar; graduado em Direito pela Universidade Federal do Rio Grande do Norte. Natal/RN, Brasil. 